\title{
Espectro de lesiones en imágenes de tomografía computarizada y resonancia magnética, en deportistas que participaron en los Juegos Olímpicos de la Juventud Buenos Aires 2018. Nuestra experiencia
}

Pablo M. Sartori, Agustín Viña, Andrés Arcos, Fernando Roberts, Patricia Barasatián, Braian Yampolski

Servicio de Tomografía Computada y Resonancia Magnética, Departamento de Diagnóstico por Imágenes, Sanatorio "Dr. Julio Méndez", Ciudad Autónoma de Buenos Aires, Argentina

\begin{abstract}
RESUMEN
Objetivo: Describir las lesiones evaluadas por imágenes de los atletas que participaron en los Juegos Olímpicos de la Juventud Buenos Aires 2018. Materiales y Métodos: Se llevó a cabo un estudio descriptivo con una serie de 38 deportistas que participaron en los Juegos Olímpicos de la Juventud Buenos Aires 2018 y se sometieron a estudios por imágenes. Se analizaron los siguientes datos: distribución por sexo, edad, país, disciplina deportiva y hallazgos patológicos. Resultados: Se atendió a más deportistas mujeres $(63,15 \%)$, la mayoría (31,57\%) era de América del Sur. El atletismo fue la disciplina que más pacientes aportó (7 estudios). Predominaron las lesiones de los tejidos blandos de los miembros inferiores $(51,51 \%)$. Conclusiones: Las atletas fueron quienes más se realizaron estudios por imágenes, y las lesiones más frecuentes fueron las de los tejidos blandos de los miembros inferiores. Palabras clave: Lesiones deportivas; tomografía computarizada; resonancia magnética.
\end{abstract}

Nivel de Evidencia: IV

Spectrum of lesions observed by computed tomography and magnetic resonance imaging scans in young athletes that participated in the 2018 Youth Olympic Games in Buenos Aires

\section{ABSTRACT}

Objectives: To describe the sports-related injuries observed in young athletes that participated in the 2018 Youth Olympic Games in Buenos Aires. Materials and Methods: This was a descriptive study including 38 athletes that participated in the 2018 Youth Olympic Games in Buenos Aires and who were evaluated using imaging techniques. Athlete's distribution was analyzed by sex, age, sports activity and pathologic findings. Results: There were 4012 athletes that participated in the 2018 Youth Olympic Games in Buenos Aires, and, surprisingly, the number of male and female athletes was exactly the same. Injuries in female athletes were the most common (63.15\%), most of them occurring in athletes of South American origin (31.57\%). Athletics was the sport practiced by most patients ( 7 studies). Soft tissue injuries were most common in female athletes and mostly involved the lower limb $(51.51 \%)$. Conclusions: The number of imaging studies carried out was higher in young female athletes, and the most common injuries were soft tissue injuries of the lower limb.

Keywords: Sports-related injuries; computed tomography scan; magnetic resonance imaging.

Level of Evidence: IV

\section{INTRODUCCIÓN}

La práctica deportiva no está exenta de que ocurran lesiones, aunque quienes la realizan sean profesionales entrenados o con amplia experiencia en una actividad determinada.

Recibido el 16-1-2019. Aceptado luego de la evaluación el 16-6-2019 • Dr. PABLO M. SARTORI • pablomsar @yahoo.com.ar (ID)

Cómo citar este artículo: Sartori PM, Viña A, Arcos A, Roberts F, Barasatián P, Yampolski B. Espectro de lesiones en imágenes de tomografía computarizada y resonancia magnética, en deportistas que participaron en los Juegos Olímpicos de la Juventud Buenos Aires 2018. Nuestra experiencia. Rev Asoc Argent Ortop Traumato/ 2019;84(4):372-385. http://dx.doi.org/10.15417/ issn. 1852-7434.2019.84.4.955 
La energía cinética y muscular desarrollada conlleva el riesgo de que se produzcan lesiones musculoligamentarias y de tejidos blandos, ya sea en el entrenamiento o durante la competencia. ${ }^{1}$

Los movimientos repetitivos propios del entrenamiento con ejercicios programados o los contactos inesperados durante la competencia pueden desencadenar lesiones musculoesqueléticas o de tejidos blandos, tanto en atletas entrenados y profesionales, como en deportistas aficionados.

Durante octubre de 2018, en la Ciudad Autónoma de Buenos Aires, se llevó a cabo la tercera edición de los Juegos Olímpicos (JJ.OO.) de la Juventud, a la que concurrieron 4012 atletas de 206 países (Figura 1). ${ }^{2,3}$

El Gobierno de la Ciudad Autónoma de Buenos Aires eligió a nuestro Centro (Diagnóstico Mediter. Sanatorio "Dr. Julio Méndez") (ObSBA) para realizarle los estudios por imágenes -tomografía computarizada (TC) y resonancia magnética (RM)-, a aquellos deportistas que sufrieran lesiones y requirieran una evaluación por medio de estos estudios. ${ }^{4}$ Esto representó una oportunidad única de participar en el rápido diagnóstico de las lesiones que sufrían estos pacientes.

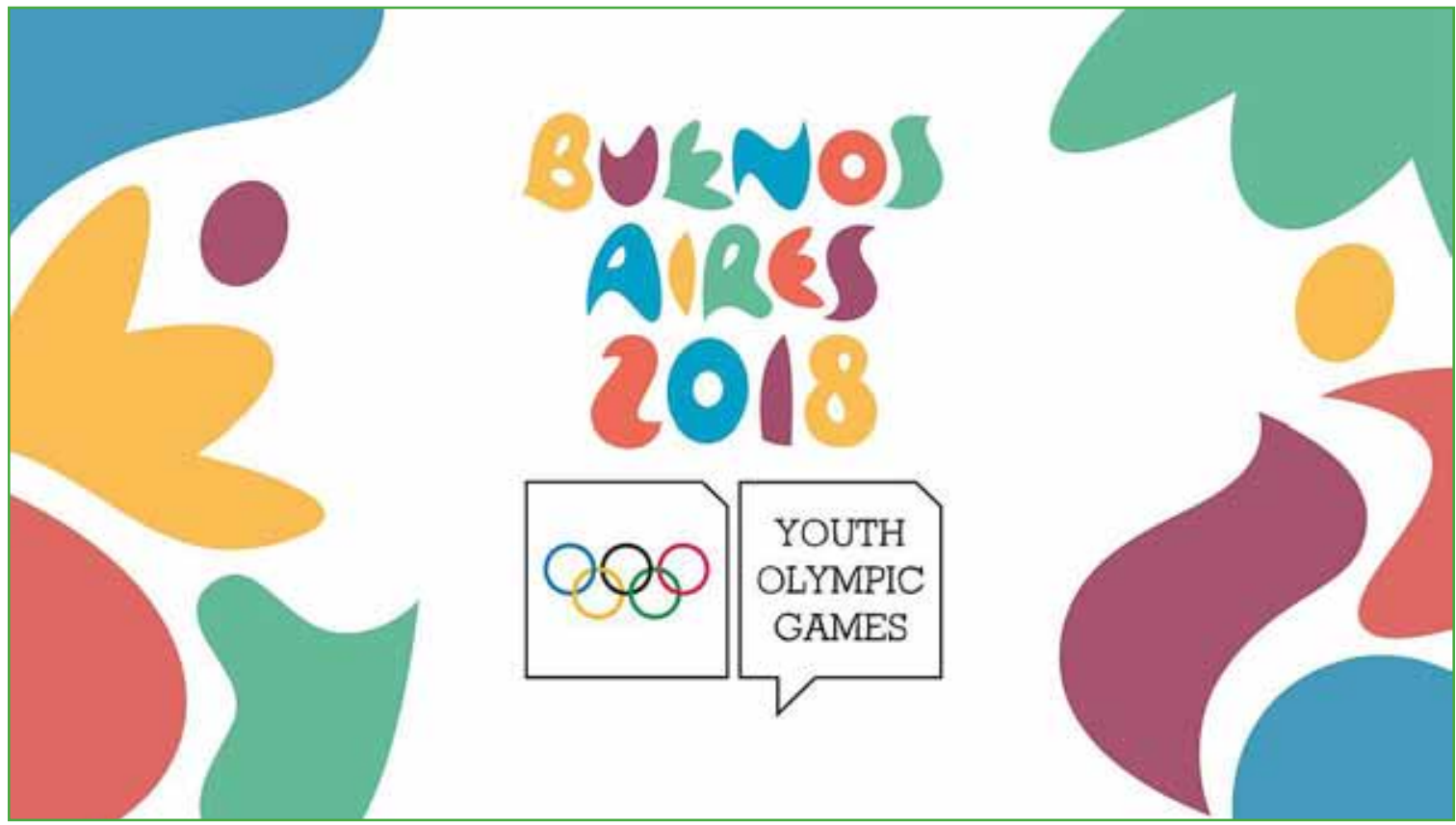

Figura 1. Afiche de los Juegos Olímpicos de la Juventud Buenos Aires 2018.

\section{MATERIALES Y MÉTODOS}

Se llevó a cabo un estudio descriptivo de corte transversal en los atletas que participaron en los JJ.OO. de la Juventud Buenos Aires 2018, del 6 al 18 de octubre, ${ }^{2}$ y sufrieron lesiones durante el entrenamiento o en la competencia, y requirieron una TC o RM.

El período del estudio abarcó la duración de los JJ.OO. de la Juventud, y se extendió dos días más (del 6 al 20 de octubre de 2018).

Se incluyó a 38 atletas de entre 15 a 18 años que sufrieron una lesión deportiva y necesitaron de estudios por imágenes para diagnosticarla.

Los datos sobre nacionalidad, edad, sexo, tipo de estudio, presencia y tipo de lesión, fueron tomados de la anamnesis, el pedido médico y el informe del estudio por imágenes.

Para caracterizar las lesiones de los deportistas olímpicos se tomaron las variables: sexo (masculino/femenino), edad (15-18 años), estructura anatómica afectada (miembro superior/inferior), lateralidad (derecha/izquierda), deporte practicado, tipo de tejido lesionado (óseo, muscular, tejidos blandos y mixtas).

Los informes fueron elaborados por cinco especialistas en imágenes con amplia experiencia y capacitados en informes del sistema musculoesquelético y neurorradiología. 
Los resultados obtenidos se expresan en números absolutos y en porcentajes.

Los estudios se realizaron con un Tomógrafo Phillips Evo 2 de 16 filas y un Resonador Philips Ingenia 1,5 T.

\section{RESULTADOS}

La muestra estaba integrada por 38 atletas (14 del sexo masculino [36,84\%] y 24 del sexo femenino [63,15\%]), provenientes de 29 países (Tabla 1). En la Figura 2, se detalla el origen de los atletas atendidos, por continente. Las edades oscilaban entre los 15 y 18 años (media 16.81).

Tabla 1. Países y número de atletas atendidos

\begin{tabular}{|c|c|c|}
\hline Países & Atletas atendidos & Porcentajes \\
\hline Antigua y Barbuda & 1 & $2,63 \%$ \\
\hline Argentina & 4 & $10,52 \%$ \\
\hline Bolivia & 1 & $2,63 \%$ \\
\hline Brasil & 1 & $2,63 \%$ \\
\hline Chile & 1 & $2,63 \%$ \\
\hline Colombia & 3 & $7,89 \%$ \\
\hline Congo & 2 & $5,13 \%$ \\
\hline España & 1 & $2,63 \%$ \\
\hline Estonia & 1 & $2,63 \%$ \\
\hline Federación Rusa (Rusia) & 1 & $2,63 \%$ \\
\hline Francia & 1 & $2,63 \%$ \\
\hline Gambia & 1 & $2,63 \%$ \\
\hline Gran Bretaña & 1 & $2,63 \%$ \\
\hline Guatemala & 1 & $2,63 \%$ \\
\hline Hungría & 1 & $2,63 \%$ \\
\hline República de Irlanda & 1 & $2,63 \%$ \\
\hline Kazajistán & 2 & $5,26 \%$ \\
\hline Letonia & 2 & $5,26 \%$ \\
\hline República de Macedonia & 1 & $2,63 \%$ \\
\hline Marruecos & 1 & $2,63 \%$ \\
\hline Omán & 1 & $2,63 \%$ \\
\hline Perú & 1 & $2,63 \%$ \\
\hline República Checa & 1 & $2,63 \%$ \\
\hline República Dominicana & 1 & $2,63 \%$ \\
\hline Sudáfrica & 2 & $5,26 \%$ \\
\hline Tailandia & 1 & $2,63 \%$ \\
\hline Trinidad y Tobago & 1 & $2,63 \%$ \\
\hline Turkmenistán & 1 & $2,63 \%$ \\
\hline Venezuela & 1 & $2,63 \%$ \\
\hline Total & 38 & $100 \%$ \\
\hline
\end{tabular}




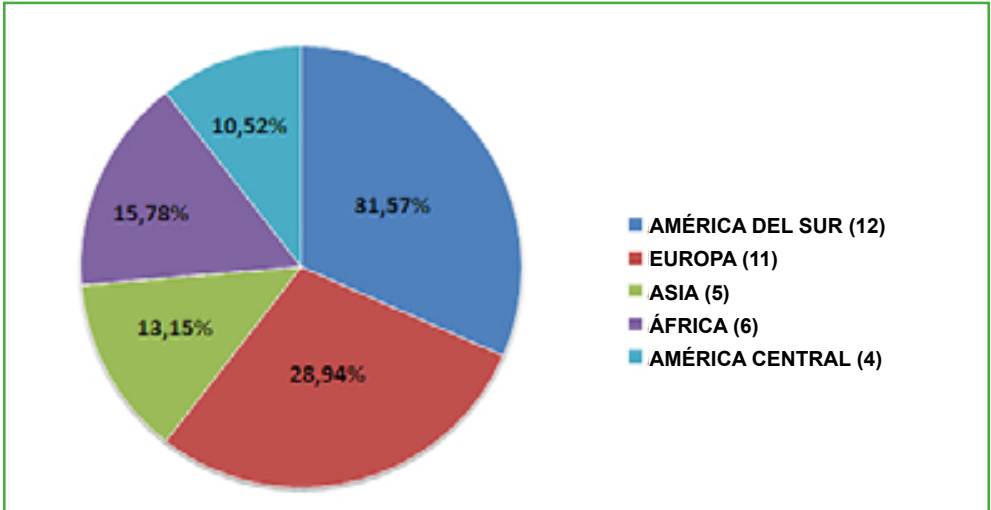

Figura 2. Origen de los atletas, por continente.

Se solicitaron, en total, 44 estudios (regiones): 6 (13,63\%) TC y $38(83,36 \%)$ RM. Solo cinco atletas $(13,15 \%)$ requirieron estudios dobles (dos regiones distintas o similares, estudiadas mediante TC o RM) (Tabla 2, Figura 3).

Tabla 2. Regiones solicitadas

\begin{tabular}{|c|c|c|c|c|c|}
\hline Región & TC & $\mathbf{R M}$ & Derecha/o & Izquierda/o & Porcentajes \\
\hline \multicolumn{6}{|l|}{ Sistema nervioso central } \\
\hline Cerebro & & 2 & & & $4,5 \%$ \\
\hline Angio-RM de cerebro & & 1 & & & $2,2 \%$ \\
\hline \multicolumn{6}{|l|}{ Raquis } \\
\hline Columna lumbar & & 2 & & & $4,5 \%$ \\
\hline \multicolumn{6}{|l|}{ Miembro superior } \\
\hline Articulación esternoclavicular & & 1 & 1 & 1 & $2,2 \%$ \\
\hline Hombro & & 1 & 1 & & $2,2 \%$ \\
\hline Codo & & 1 & 1 & & $2,2 \%$ \\
\hline Muñeca & 2 & 2 & 1 & 3 & $9,09 \%$ \\
\hline Mano & & 1 & & 1 & $2,2 \%$ \\
\hline \multicolumn{6}{|l|}{ Miembro inferior } \\
\hline Caderas** & 1 & 1 & 2 & 2 & $4,5 \%$ \\
\hline Muslo & & 1 & 1 & & $2,2 \%$ \\
\hline Rodilla & & 14 & 7 & 7 & $31,8 \%$ \\
\hline Pierna & 2 & 1 & 2 & 1 & $6,8 \%$ \\
\hline Tobillo & 1 & 9 & 5 & 5 & $22,7 \%$ \\
\hline Pie & & 1 & & 1 & $2,2 \%$ \\
\hline Totales & 6 & 38 & 21 & 21 & $100 \%$ \\
\hline
\end{tabular}

* abarca ambas articulaciones esterno-claviculares

**abarca a ambas caderas

$\mathrm{TC}=$ tomografía computarizada, $\mathrm{RM}=$ resonancia magnética . 


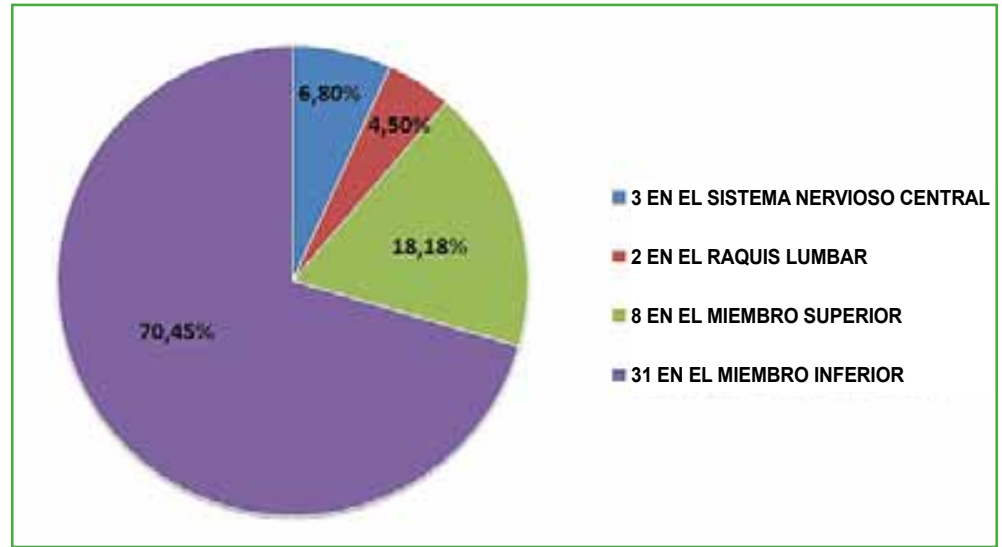

Figura 3. Regiones solicitadas.

De los 32 deportes que formaban parte de la competencia, nuestro Servicio atendió a participantes de 17 disciplinas (Tabla 3).

Si se discrimina por lateralidad (derecha/izquierda) sobre la base de 42 estudios de los miembros (no se consideran los estudios del sistema nervioso central ni de raquis) y teniendo en cuenta que el estudio de caderas y la articulación esternoclavicular abarca a ambas regiones, los resultados fueron: 21 (50\%) estudios de miembros (superior e inferior) derechos y $21(50 \%)$ izquierdos.

Tabla 3. Disciplinas deportivas atendidas

\begin{tabular}{|l|c|c|}
\hline Disciplina deportiva & Atletas atendidos & Porcentajes \\
\hline Atletismo & 7 & $18,42 \%$ \\
\hline Básquetbol 3 x 3 & 1 & $2,63 \%$ \\
\hline Vóley playa & 2 & $5,26 \%$ \\
\hline Balonmano playa & 1 & $2,63 \%$ \\
\hline Boxeo & 2 & $5,26 \%$ \\
\hline Ciclismo & 3 & $7,89 \%$ \\
\hline Futsal & 4 & $10,52 \%$ \\
\hline Gimnasia artística & 6 & $15,78 \%$ \\
\hline Hockey 5 & 1 & $2,63 \%$ \\
\hline Judo & 1 & $2,56 \%$ \\
\hline Lucha & 2 & $5,26 \%$ \\
\hline Natación & 1 & $2,63 \%$ \\
\hline Patinaje de velocidad sobre ruedas & 1 & $2,63 \%$ \\
\hline Pentatlón & 1 & $2,63 \%$ \\
\hline Rugby 7 & 2 & $5,26 \%$ \\
\hline Taekwondo & 1 & $2,63 \%$ \\
\hline Tenis & 2 & $5,26 \%$ \\
\hline Total & $\mathbf{3 8}$ & $\mathbf{1 0 0 \%}$ \\
\hline
\end{tabular}


En la Figura 4, se muestran los resultados obtenidos si, a la valoración por lateralidad, se le suma la consideración por miembro superior/inferior.

Del total de estudios solicitados (44 regiones), 11 (25\%) fueron informados como normales; dos $(18,18 \%)$ fueron TC y $9(81,81 \%)$, RM (Tabla 4$)$.

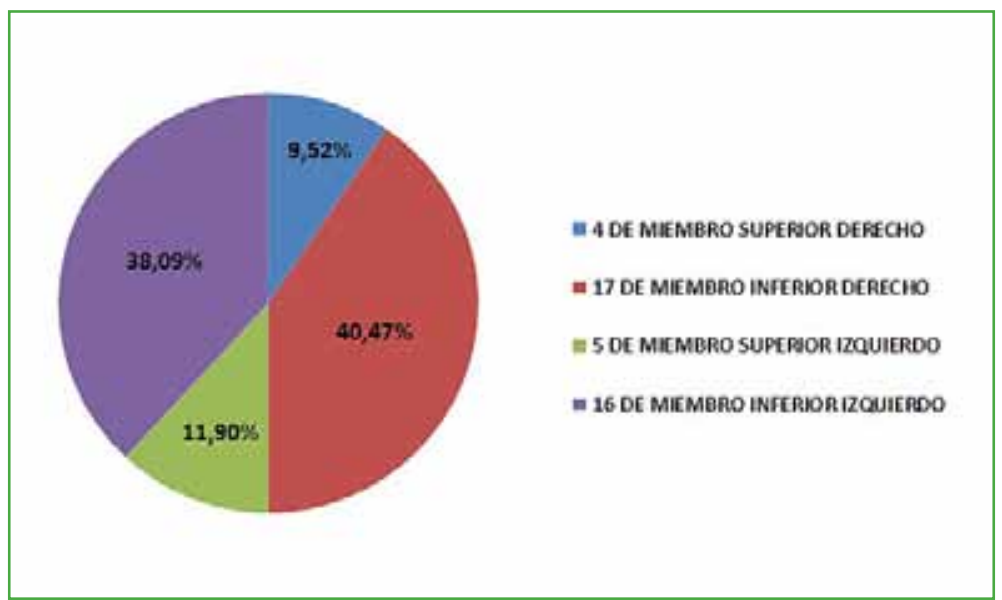

Figura 4. Diferencia según el miembro y la lateralidad.

Tabla 4. Hallazgos normales informados

\begin{tabular}{|c|c|c|c|c|}
\hline Región & TC & $\mathbf{R M}$ & Derecha/o & Izquierda/o \\
\hline \multicolumn{5}{|l|}{ Sistema nervioso central } \\
\hline Cerebro & & 2 & & \\
\hline Angio-RM intracraneal & & 1 & & \\
\hline \multicolumn{5}{|l|}{ Raquis } \\
\hline Columna lumbar & & 1 & & \\
\hline \multicolumn{5}{|l|}{ Miembro superior } \\
\hline Hombro & & 1 & 1 & \\
\hline Codo & & 1 & 1 & \\
\hline \multicolumn{5}{|l|}{ Miembro inferior } \\
\hline Caderas" & 1 & 1 & & \\
\hline Muslo & & 1 & 1 & \\
\hline Rodilla & & 1 & 1 & \\
\hline Tobillo & 1 & & 1 & \\
\hline Totales & 2 & 9 & 5 & $\mathbf{0}$ \\
\hline
\end{tabular}

$\mathrm{TC}=$ tomografía computarizada, $\mathrm{RM}=$ resonancia magnética. $*$ Abarca ambas caderas.

Todos los estudios que valoraron el miembro superior o el inferior considerados como normales fueron derechos. Por otro lado, los 33 estudios (75\%) restantes fueron informados como patológicos (29 RM [87,87\%] y 4 $[12,12 \%]) \mathrm{TC})$. 
Trece $(39,39 \%)$ de los 33 estudios con informes patológicos correspondieron al sexo masculino y 20 (60,60\%), al sexo femenino.

Las lesiones informadas como patológicas pueden clasificarse por región anatómica afectada; las que afectaban al miembro superior fueron seis (18,18\%): articulación costoclavicular (1 caso, 3,03\%); muñeca (4 casos, 12,12\%) y mano (1 caso, 3,03\%). Mientras que las lesiones del miembro inferior fueron 27 (81,81\%): rodilla (13 casos, $48,14 \%$ ); pierna ( 3 casos, $11,11 \%$ ); tobillo ( 9 casos, $33,33 \%$ ) y pie ( 1 caso, $3,70 \%$ ). Los distintos tipos de lesiones pueden interrelacionarse con el miembro afectado (Tabla 5).

Finalmente, en la valoración del raquis lumbar, un estudio $(3,03 \%)$ fue informado como patológico.

Las lesiones fueron clasificadas como: óseas, musculares, de tejidos blandos (tendones, meniscos, ligamentos y cartílagos) y, por último, mixtas (que afectan como mínimo a dos o más de las anteriormente descritas). Los hallazgos se describen en la Figura 5.

Tabla 5. Clasificación de los hallazgos patológicos según la estructura afectada

\begin{tabular}{|l|c|c|c|c|c|}
\hline & Lesión ósea & Lesión muscular & Lesión de tejidos blandos & Lesiones mixtas & Totales \\
\hline Miembro superior & 3 & -- & 2 & 1 & $\mathbf{6}$ \\
\hline Miembro inferior & 9 & 1 & 13 & 3 & $\mathbf{2 6}$ \\
\hline Raquis & -- & -- & 1 & -- & $\mathbf{1}$ \\
\hline Totales & $\mathbf{1 2}$ & $\mathbf{1}$ & $\mathbf{1 6}$ & $\mathbf{4}$ & $\mathbf{3 3}$ \\
\hline
\end{tabular}

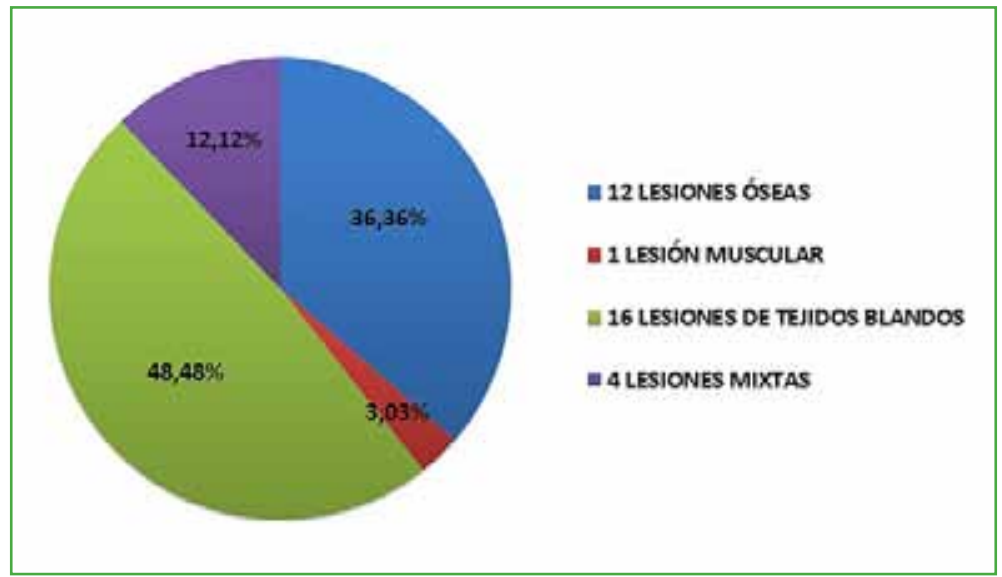

Figura 5. Clasificación de las lesiones.

Hubo tres $(9,09 \%)$ lesiones óseas en el miembro superior y 9 (27,27\%) en el inferior.

En relación con las lesiones musculares, solo una $(3,03 \%)$ afectaba el miembro inferior.

Las lesiones de los tejidos blandos comprometían: dos (6,06\%) el miembro superior, 13 (39,39\%) el miembro inferior y una $(3,03 \%)$ el raquis lumbar. En tanto que las lesiones mixtas fueron: una $(3,03 \%)$ en el miembro superior y tres $(9,09 \%)$ en el inferior.

Las distintas patologías informadas se muestran en la Tabla 6 y las Figuras 6-12. 
Tabla 6. Lesiones informadas

\begin{tabular}{|c|c|c|c|c|}
\hline Lesión & Miembro superior & Miembro inferior & Raquis & Totales \\
\hline Osteoma osteoide & & 2 & & 2 \\
\hline Fibroma osificante & & 1 & & 1 \\
\hline Edema en articulaciones esterno-claviculares & 1 & & & 1 \\
\hline Fractura de huesos de la muñeca & 3 & & & 3 \\
\hline Lesión en complejo extensor de la mano & 1 & & & 1 \\
\hline Lesión del fibrocartílago triangular de la muñeca & 1 & & & 2 \\
\hline Extrusión de L5-S1 & & & 1 & 1 \\
\hline Desgarro muscular & & 3 & & 3 \\
\hline Edema óseo en la rodilla & & 1 & & 1 \\
\hline Lesión aislada del LCA & & 4 & & 4 \\
\hline Lesión del LCA asociada a lesión meniscal & & 6 & & 6 \\
\hline Fractura de hueso del tobillo & & 1 & & 1 \\
\hline Edema óseo en el tobillo & & 4 & & 4 \\
\hline Desgarro de ligamentos del tobillo & & 3 & & 3 \\
\hline Fractura de huesos del pie & & 1 & & 1 \\
\hline Totales & 6 & 27 & 1 & 34 \\
\hline
\end{tabular}

\section{DISCUSIÓN}

Este estudio es el primero realizado en lesiones durante la práctica deportiva, en el transcurso de los JJ.OO. de la Juventud Buenos Aires 2018 y permitió obtener resultados sobre las lesiones que se producen durante la práctica deportiva, ya sea en el entrenamiento o en la competencia misma.

El análisis de los resultados revela que fueron atendidos 38 deportistas: 14 del sexo masculino y 24 del sexo femenino (relación: 1,7:1 en favor de las mujeres).

Se solicitaron 44 estudios (regiones): seis TC y 38 RM (relación 6,3:1 a favor de RM), resultados lógicos dado que este último método tiene mejor resolución espacial y diferenciación tisular para localizar lesiones de partes blandas.

Diecisiete fueron las disciplinas deportivas atendidas y las que más atletas aportaron fueron: atletismo (7 atletas, $41,17 \%)$, gimnasia artística $(6,35,29 \%)$ y futsal $(4,23,52 \%)$.

Estudios de cohorte que llevaron a cabo un análisis entre distintos reportes comunicaron que la tasa de lesiones deportivas oscila entre el 0,8 y el 90,0 por mil horas de entrenamiento y entre 3,1 y 54,8 por 1000 horas de competición. ${ }^{1,5}$

El Centers for Disease Control and Prevention informa que se producen 7 millones de lesiones en general, por año y más de la mitad se relaciona con la actividad deportiva de alta competencia, en niños y jóvenes de entre 5 y 24 años de edad. ${ }^{1}$

Podemos definir como lesión deportiva a aquel daño tisular que afecta el funcionamiento de una estructura, ocasionado en la práctica de un deporte. ${ }^{5}$

En cuanto a las diferencias por sexo, las mujeres son más propensas a sufrir lesiones menores, como esguinces, mientras que los hombres suelen padecer traumatismos más graves, como desgarros y fracturas. ${ }^{5}$ Algunos colegas informan que las profesionales deportistas son más propensas que los hombres a sufrir lesiones de rodilla, ante similares niveles de alta competencia. ${ }^{5}$ 

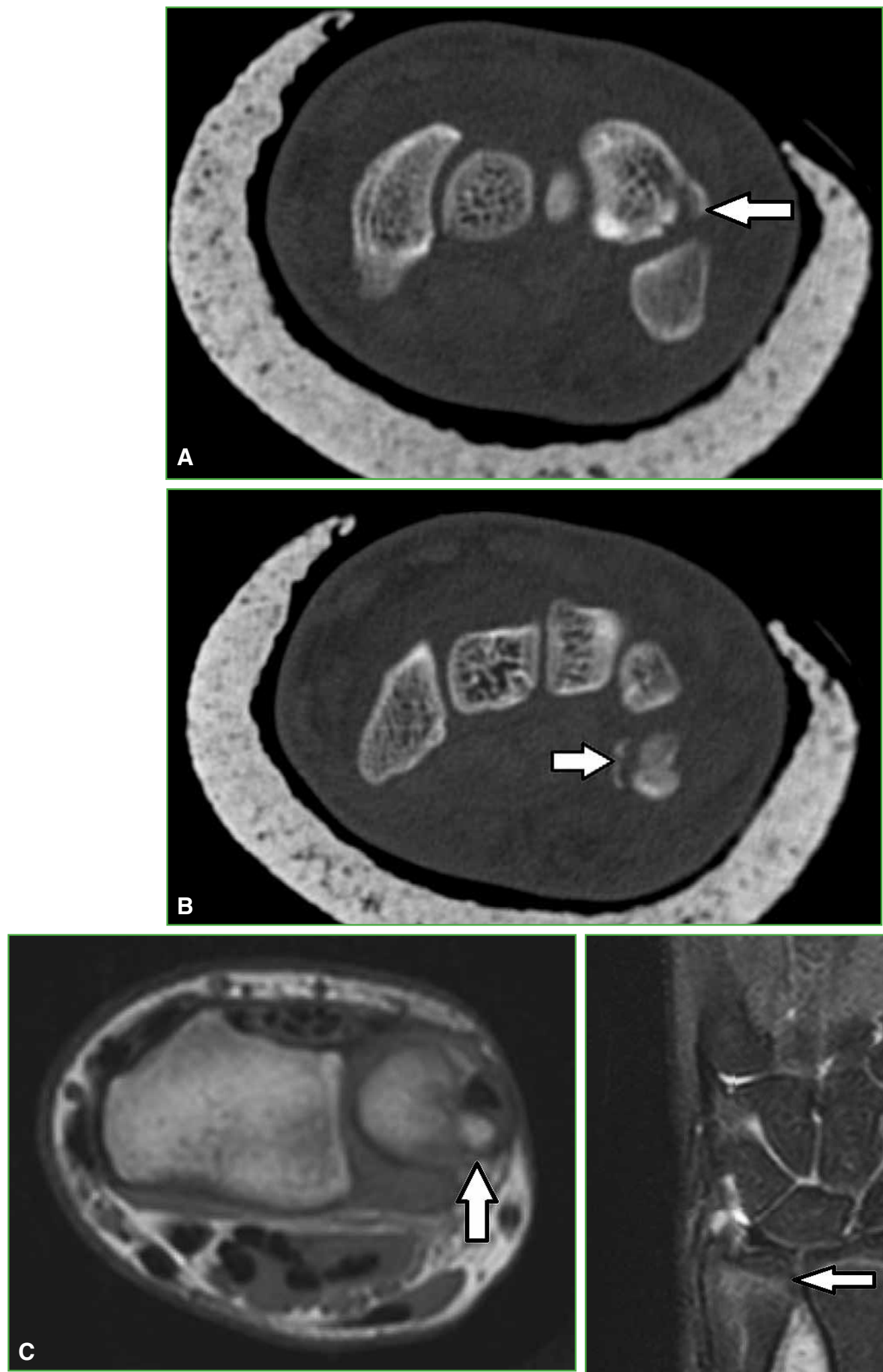

Figura 6. Fracturas de huesos de la muñeca en dos deportistas. Tomografía computarizada, cortes axiales. Se observa fractura de los huesos pisiforme (A) y piramidal (B) (flechas) de un atleta. Resonancia magnética, cortes axial T1 y coronal STIR. Se visualiza una fractura del cúbito $(\mathbf{C} \mathbf{y} \mathbf{D})$ (flechas) en otro atleta.

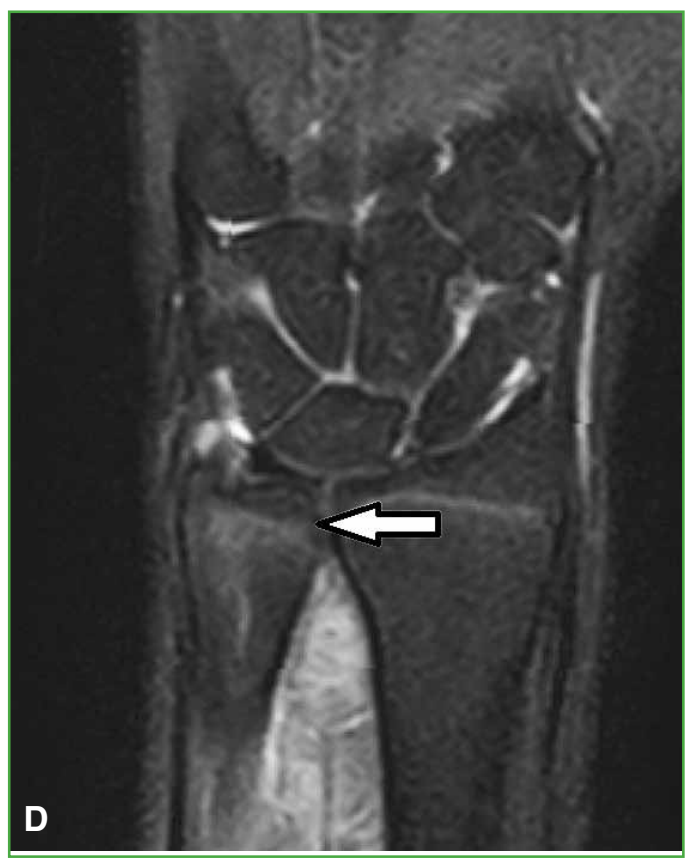



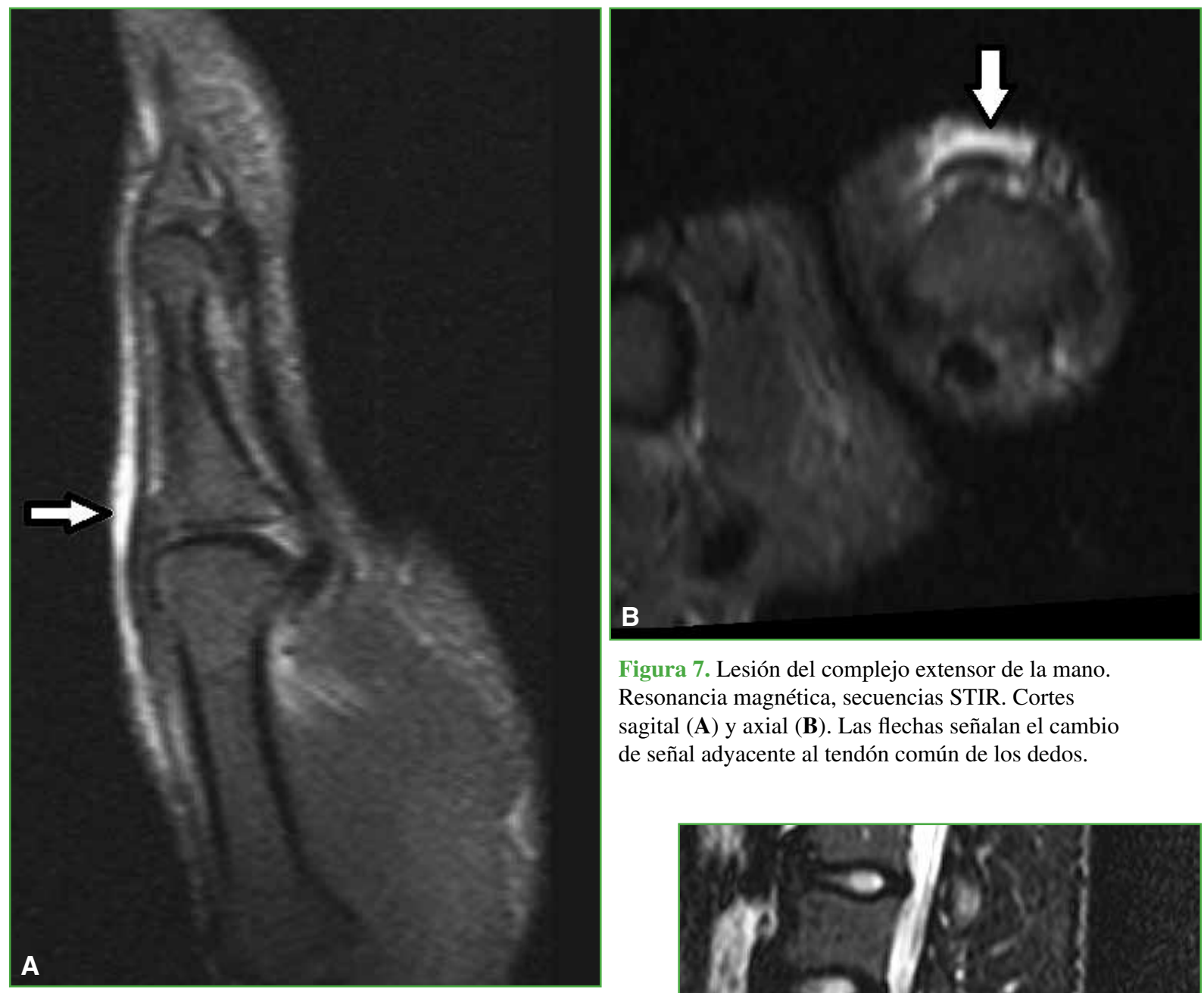

Figura 7. Lesión del complejo extensor de la mano. Resonancia magnética, secuencias STIR. Cortes sagital (A) y axial (B). Las flechas señalan el cambio de señal adyacente al tendón común de los dedos.

Figura 8. Resonancia magnética, corte sagital ponderado en secuencia T2. La flecha señala la extrusión de L5-S1.

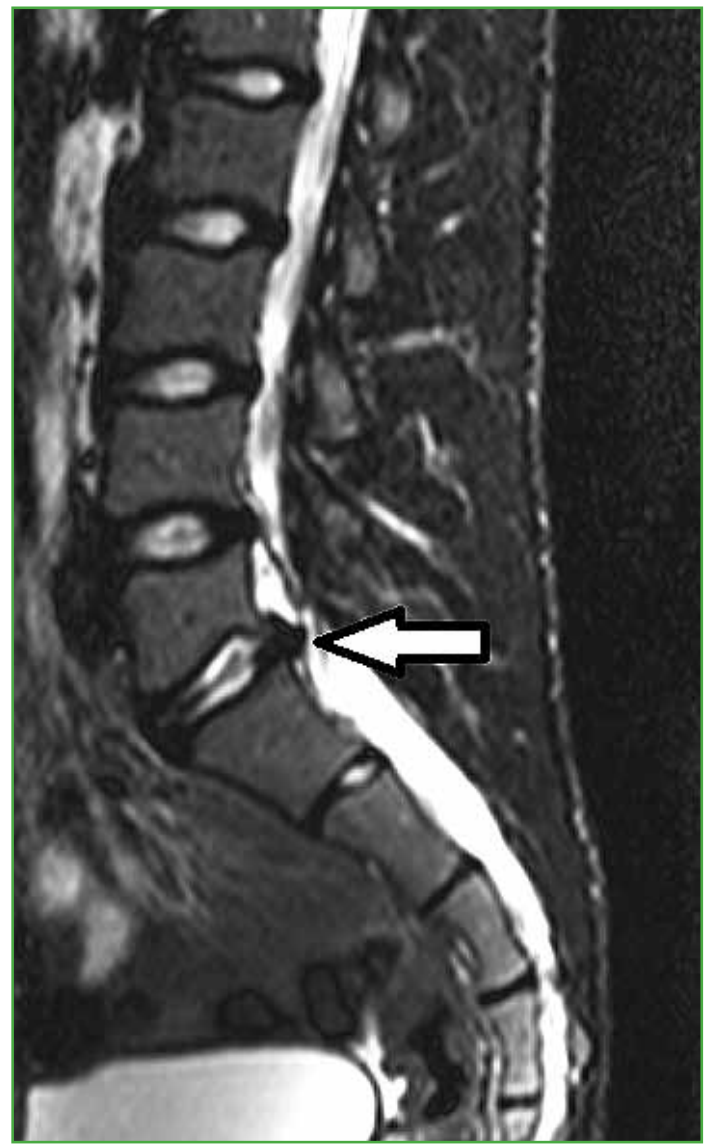



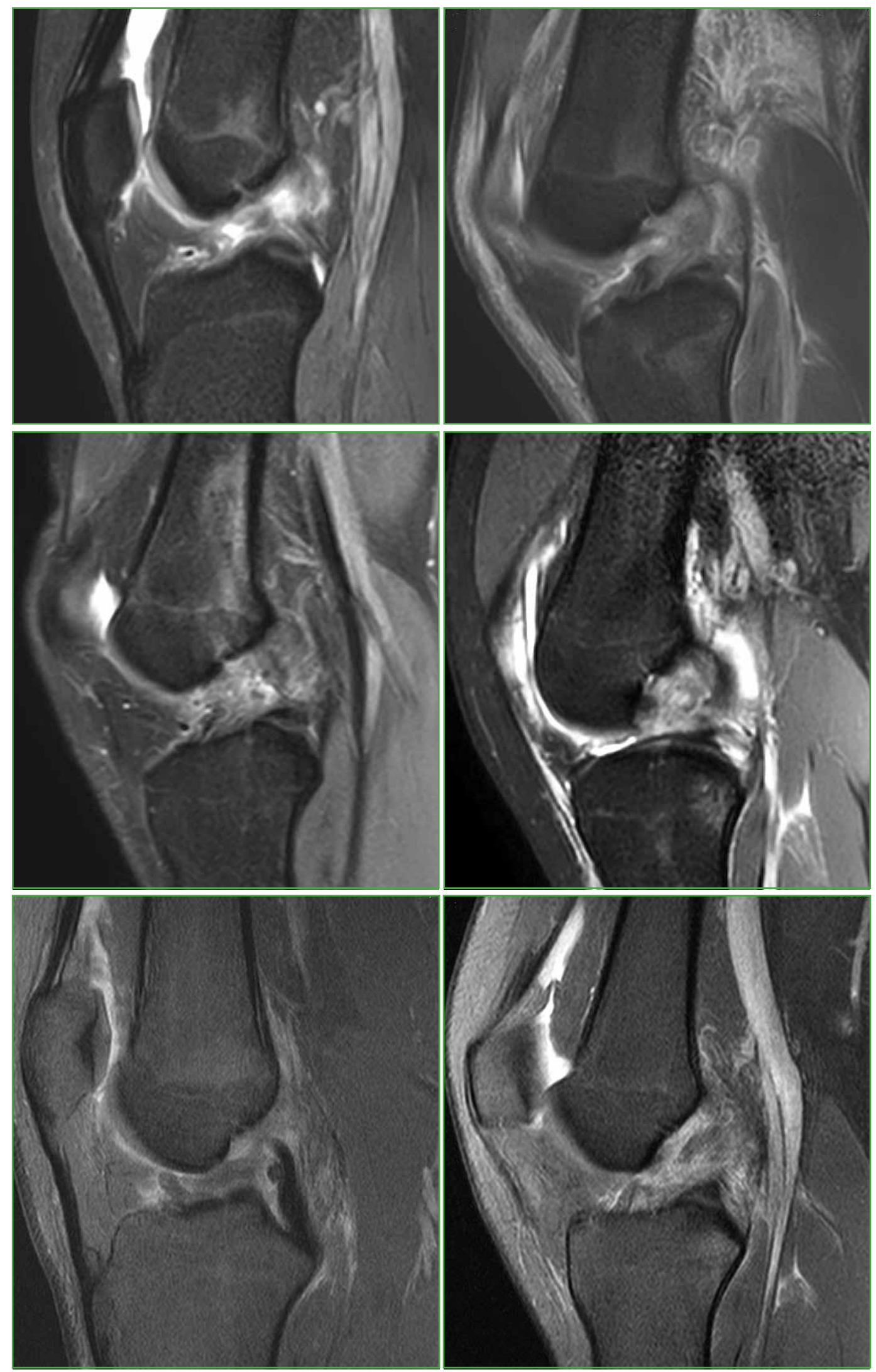

Figura 9. Resonancia magnética de rodilla. Imágenes de lesión del ligamento cruzado anterior en distintos atletas. 


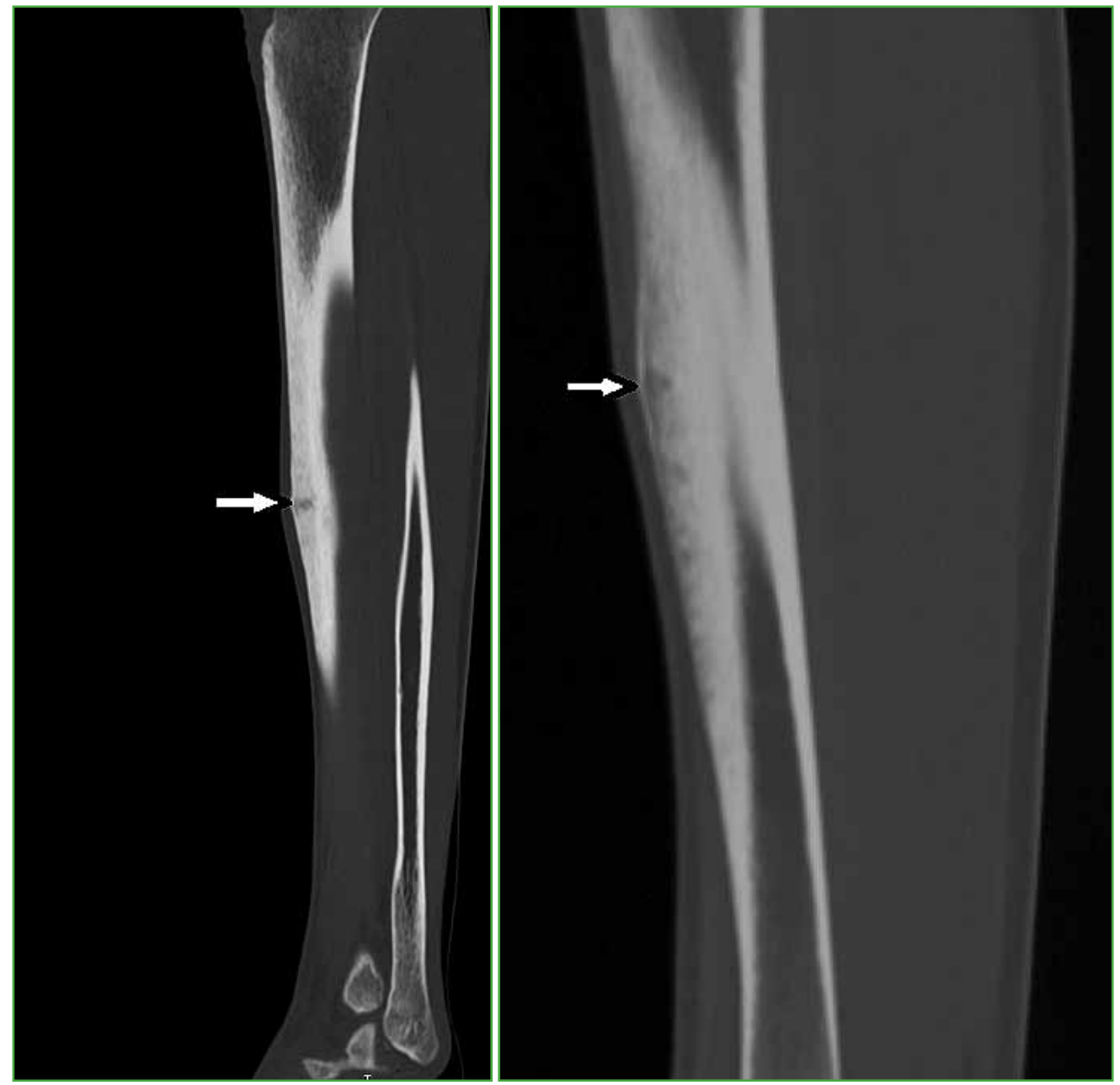

Figura 10. Osteoma osteoide. Tomografía computarizada, cortes sagitales de la pierna que muestran lesiones hipodensas subcorticales (flechas) que comprometen el periostio de las tibias. Dos atletas presentaron estas lesiones en la tibia.
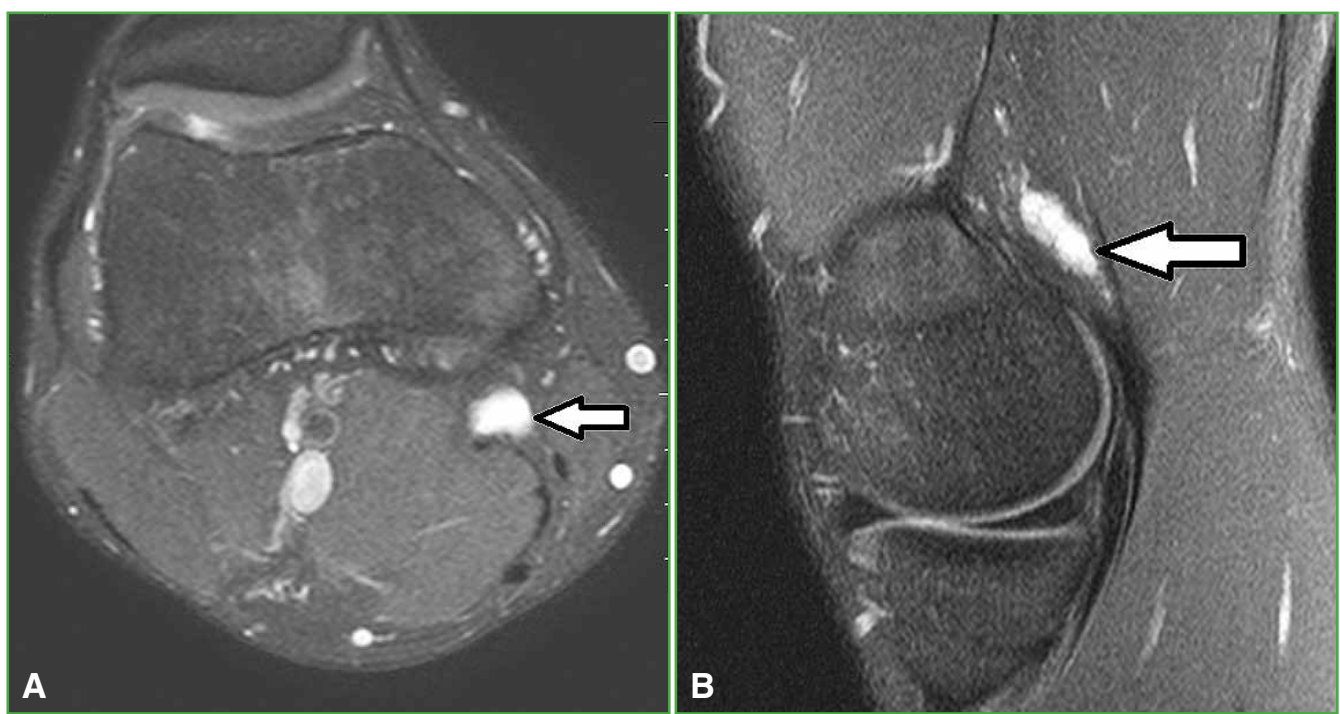

Figura 11. Resonancia magnética de rodilla, secuencia STIR. Cortes axial (A) y sagital (B). Lesión focal en la inserción distal del semimembranoso después del esfuerzo durante la competencia (flechas). 

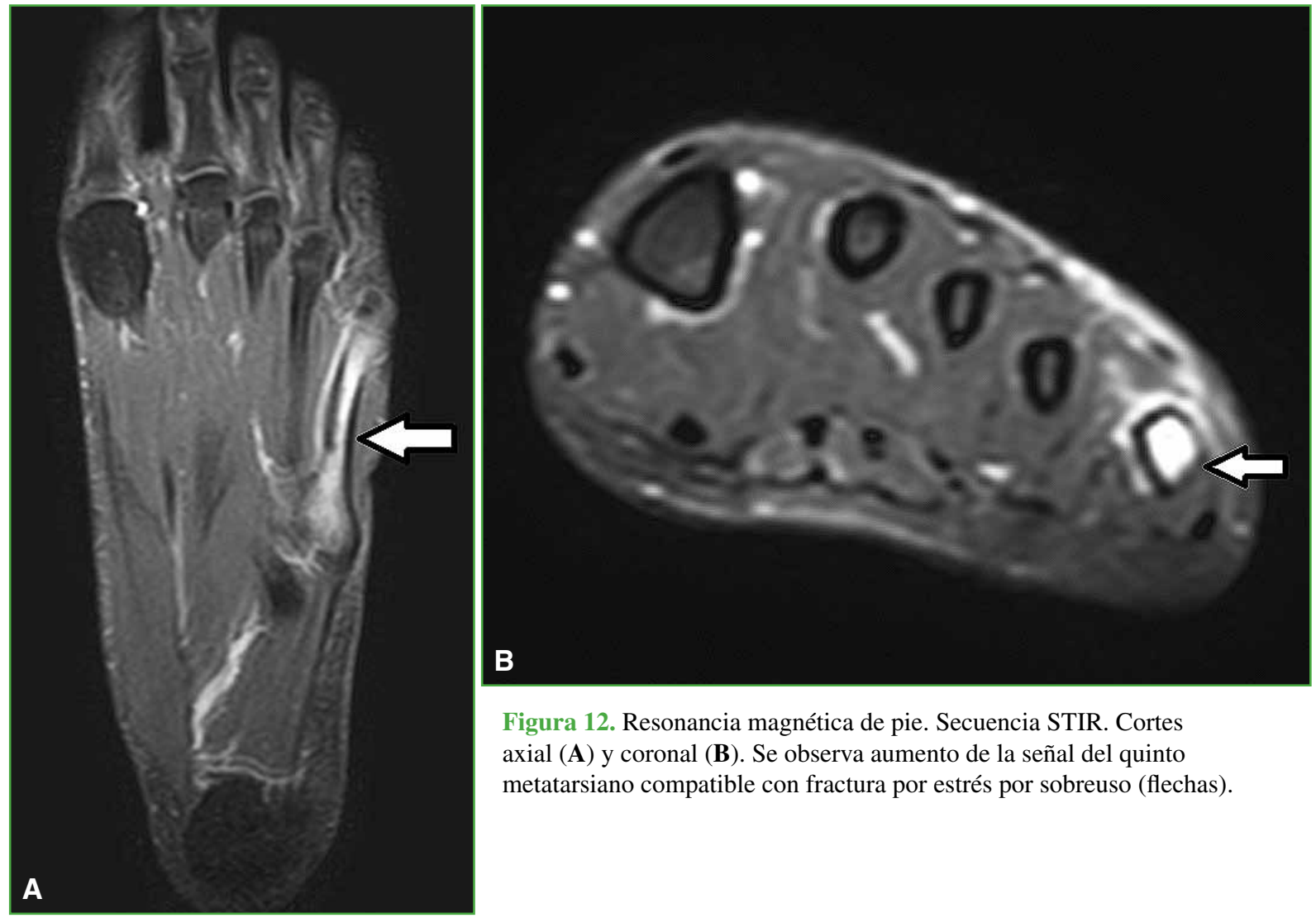

Figura 12. Resonancia magnética de pie. Secuencia STIR. Cortes axial (A) y coronal (B). Se observa aumento de la señal del quinto metatarsiano compatible con fractura por estrés por sobreuso (flechas).

En nuestro grupo de atletas, la relación mujer:hombre con lesiones es de 1,5, con 20 estudios informados como patológicos en mujeres $(60,60 \%)$ y 13 en hombres $(39,39 \%)$.

Osorio y cols. reportan que los deportes que más incidencia de lesiones tienen son: judo, fútbol, básquetbol, hockey y vóley, por ser actividades de contacto, con giros bruscos, aceleraciones y desaceleraciones, así como barridos y forcejeos con los adversarios. ${ }^{1,5}$

Habitualmente el sitio de la lesión está íntimamente relacionado con el deporte practicado. ${ }^{5}$

La mayoría de las lesiones deportivas afectan a los miembros inferiores. ${ }^{5}$ García comunica que las lesiones más frecuentes en judocas son las tendinopatías en los miembros superiores y las ligamentarias en los miembros inferiores. ${ }^{1,5,6}$

Algunos artículos mencionan que el $80 \%$ de las lesiones afecta a los tejidos blandos (tendones, músculos, ligamentos) y que el $20 \%$ restante incluye fracturas y lesiones de órganos internos. ${ }^{5}$

En relación con el tipo de lesión, Osorio y cols. mencionan que, en los JJ.OO. de 1968 y 1974, las lesiones tratadas más frecuentes fueron: esguinces, desgarros y contusiones. ${ }^{5}$

En nuestra casuística, las lesiones más frecuentes fueron las de tejidos blandos en 16 casos (48,48\%), seguidas de las lesiones óseas en 12 atletas (33,33\%), con un neto predominio de los miembros inferiores ( 26 casos) contra seis en los miembros superiores (relación 4,3:1).

Las lesiones informadas más frecuentes fueron: desgarro del ligamento cruzado anterior, ya sea aislado o asociado a desgarro meniscal ( 9 casos, 27,27\%), seguido de fractura, edema óseo con desgarro de ligamentos del tobillo o sin él ( 8 casos, $24,24 \%$ ) y fractura de huesos de la muñeca con lesiones ligamentarias asociadas o sin ellas (5 casos, $15,15 \%)$.

Los datos que obtuvimos se aproximan a la casuística internacional.

Nuestro trabajo presenta algunas limitaciones, como el escaso número de atletas lesionados o no poder conocer el mecanismo de la lesión en cada caso. 


\section{CONCLUSIÓN}

Comunicamos nuestra experiencia con deportistas jóvenes de elite y las lesiones más frecuentes que ocurren durante la participación en los JJ.OO. de la Juventud Buenos Aires 2018.

Esperamos que esta información sea de utilidad en estudios futuros y sirva de base de datos para análisis posteriores.

\section{Agradecimientos \\ A Melina Gualtieri por su colaboración en los gráficos, a Jonathan Curcio, Matías Morillo y Eliana Rodríguez, por la colabo- ración en la búsqueda de datos administrativos.}

Conflicto de intereses: Los autores no declaran conflictos de intereses.

\section{BIBLIOGRAFÍA}

1. Villaquirán A, Portilla Dorado E, Vernaza Pinzón P. Caracterización de la lesión deportiva en atletas caucanos con proyección a Juegos Deportivos Nacionales. Rev Univ Salud 2016;18(3):541-9. http://dx.doi.org/10.22267/ rus.161803.59

2. Todo lo que tenés que saber de los Juegos Olímpicos de la Juventud Buenos Aires 2018. Disponible en: https:// www.infobae.com/deportes-2/2018/08/26/todo-lo-que-tenes-que-saber-de-los-juegos-olimpicos-de-la-juventudbuenos-aires-2018/. Consulta: 2 de enero de 2019

3. Buenos Aires 2018. Disponible en: https://www.buenosaires2018.com/sports?lng=es. Consulta: 30 de octubre de 2018

4. Atletas en el Sanatorio Julio Méndez. Disponible en: https://www.lapoliticaonline.com/nota/115942-atletas-en-elsanatorio-mendez/. Consulta: 9 de enero de 2019

5. Osorio Ciro J, Clavijo Rodríguez M, Arango E, Patiño Giraldo S, Gallego Ching I. Lesiones deportivas. IATREIA 2007; 20(2):167-77. https://www.redalyc.org/articulo.oa?id=1805/180513859006

6. García Garcés E. Lesiones en el judo de alta competición, actuación del deportista ante las mismas y valoración de los tratamientos de fisioterapia. Fisioterapia 2008;30(2):79-86. http://dx.doi.org/10.1016/S0211-5638(08)72961-4 